\title{
Voluntary Learning Exercises and Extracurricular Learning Support: Toward the Improvement of Learning Behavior and Learning Outcomes
}

\author{
Koji Sakai ${ }^{1}$, Issei Abe ${ }^{1}$, Daisetsu Fujita ${ }^{1}$, Kenta Naka ${ }^{2}$ \\ ${ }^{1}$ Kyoto Koka Women's University \\ ${ }^{2}$ Work Academy Corporation
}

\begin{abstract}
Continuing from an earlier 2015 project, reported in Sakai et al. [5], we assigned our students voluntary learning tasks in addition to the required homework in the course "ICT Exercise" in 2016. A learning advisor and student tutors were employed to support the students in tackling outside the class. The number of visits for consultation increased 2.0 times compared to that of 2015. Most of the consultations were related to the required homework or the voluntary learning tasks. Comparing the data from the two years, we see that the number of submissions increased largely for a simple task on character input, whereas decreased by half for a difficult task on a practice drill. The student group that completed the voluntary learning tasks showed higher learning outcomes than the group that did not. However, the learning outcomes for all students show gradually decline over three years (2014 to 2016), though the number of visits to the learning advisor and the submission rate for the voluntary learning tasks increased every year. This could be because students have recently tended to avoid using PCs because of the spread of personal smart tablets in Japan. We discuss methods to support learning outside the class and to improve the learning outcomes of all students.
\end{abstract}

\section{Introduction}

In Kyoto Koka Women's University, ICT Exercises I and II have been offered to all first-year students to train them in the basics of computer literacy and information utilization. As Sakai and Abe [3] mentioned, ICT Exercise I is offered in the first half of the year so the students gain knowledge of Microsoft Office, computers, the internet, and so on. ICT Exercise II, offered in the latter half of the school year, hones the students' skills already learned in ICT Exercise I. Computer literacy and information utilization are generic skills required for all specialized courses and so must be mastered by students belonging to any department, such as Psychology and Nursing.

As Abe and Sakai [1] mentioned, the following three systems have been applied in our university to increase the understanding of ICT Exercise. First, in a class, the main lecturer instructs the students and sub-lecturer responds to questions from them. Second, by arranging two or more classes in a particular day and time, we organize two levels of classes: the standard and the basic. The textbook is the same in both classes, but the course contents are slightly changed according to the level of the class. Third, if students fail to grasp the course content or the homework in class, they can consult with their learning advisor outside the class. Additionally, the learning advisor shares the learning progress of the students and the learning initiatives of each class with the instructors by regularly meeting them or corresponding via e-mail.

There is a difference in the motivation for learning among students, even within the same level of the class. However, the lectures are conducted for the students at the average level. Therefore, the learning support outside the class should be offered both for students who are unable to keep up with the class and for those who aim at a higher level. Sakai et al. [5] initially started assigning the voluntary learning tasks in addition to the required homework from the first half of 2015 for the students to motivate themselves to a higher level. The results showed that the number of consultations with the learning advisor in 2015 increased 2.1 times more than that of 2014, when the voluntary learning tasks were not assigned. It was also shown that the student group that completed the voluntary learning tasks had higher learning outcomes compared to the group that did not submit them at all. Meanwhile, an Acceleration Program for University Education Rebuilding (AP) from 2014 to 2019 year has been adopted at our university. As an AP project, we plan to promote a learning environment that supports active learners. We proposed that the construction of a learning environment construction would certainly improve students' learning behavior, and consequently their

Figure 1 shows the causal relationships among the learning environment, learning behavior, and learning outcomes. The learning environment is the cause, while the learning behavior and learning 
outcomes are the results. In the case of ICT Exercise, the learning environment corresponds both to the assignment of the voluntary learning tasks to the class and the learning support provided outside the class. Learning behavior refers to the visits to the learning advisor and the submission of the voluntary learning tasks. Learning outcomes correspond to the test scores of the course. Sakai et al. [5] verified the hypothesis in [4] through quantitative data analysis in ICT Exercise in 2015. learning outcomes [4].

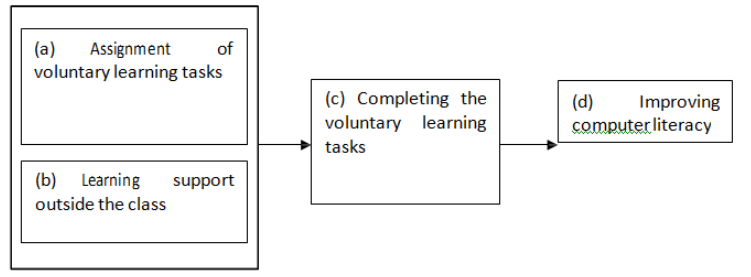

Figure 1. Relationship between the promotion of learning behavior and improvement of learning outcomes by the construction of an encouraging learning environment

However, there are two points to be considered in [5]. In the present paper, we present the collection and analysis of data from ICT Exercise in 2016, similar to the way we did in 2015 , as reported in [5]. The first point is whether the results of [5] will be similar to those obtained from first-year students of a different year. This is an issue of the reliability of data. It is possible that learning behaviors and outcomes are different every year. Therefore, we compare the data from 2015 and 2016 to verify if the results are similar. The second point is to verify whether the average of learning outcome of all the students has become higher through the assignment of voluntary learning tasks from 2015. Thus, we compare the test scores of the students from 2014 to 2016.

\section{Method}

In this section, we compare the environment of the learning support outside the class in 2015 and 2016. The method for setting the voluntary learning tasks was the same. The number of students was 374 in 2015 and 457 in 2016. The large increase of the number of students in 2016 could be because of the increase in the number of new students enrolled in our university and the recommendation by the teacher. There were two main points of difference between 2015 and 2016.

The first was that a student tutor was employed in addition to the learning advisor in 2016. Learning support was made available outside the class. The student tutor was available for three hours every week from April to the middle of June, and for five hours every week after that. The learning advisor was available for nine hours every week in 2015, and for eight hours every week in 2016. In 2015, only a learning advisor was available on Tuesdays or Wednesdays, as reported in [5].

The second point was the location of the learning support outside the class. Figure 2 shows the images of the consultation corner in 2015 and 2016. We established the consultation corner in the lobby in front of the computer training room in 2015. In 2016, we established the consultation corner in a computer room for the students to be able to use a PC or textbooks outside the class freely. A learning advisor or student tutor was stationed in the location on the specific dates and times, and they supported the students' smooth learning.

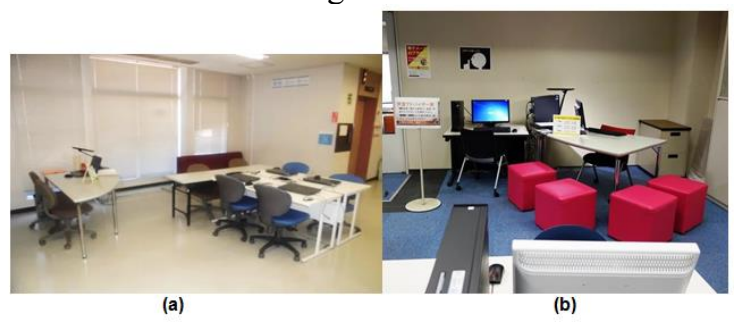

Figure 2. (a) The consultation corner where a learning advisor held office in 2015 (b) The consultation corner in 2016; in the front is where students can use a PC freely, and in the back is the consultation corner where the learning advisor or the student tutor meets students

\section{Results}

In this section, we present the data analysis that proves the setting of the voluntary learning tasks and the support of learning advisor affects learning behaviors and outcomes of students. In section 3.1, the number of consultations and rate of submissions are measured as the students' learning behaviors. In section 3.2, we compare the learning outcomes of the student group who submitted the voluntary learning tasks and the group that did not, in 2016. We also verify that the results are similar to those reported in [5]. Furthermore, we verify that learning outcomes are altered because of the improvement in the submission rate of the voluntary learning tasks from 2014 to 2016 .

\subsection{Learning behavior of students}

3.1.1. Use of the learning support outside the class. Table 1 shows the contents of consultations with the learning advisor and the student tutor in 2016.

The consultations on homework and voluntary learning tasks accounted for $97 \%$ of them. The number of consultations for the voluntary learning tasks was 1.9 times more than that for the homework. This result shows that assignment of the voluntary learning tasks would greatly influence active learning in the students outside the class. Additionally, Table 1 shows a comparison of the 
number of visits for consultation to the learning advisor in 4 months between 2015 and 2016. The number of consultations after May tended to increase in 2016, which is similar to that in 2015. The number of visits for consultation in 2016 increased 2.0 times more than that in 2015. Calculating further, the number of visits for consultation per day was an average of 12.4 in 2016 , which was 1.8 times more than the 6.8 in 2015.

Table 1. Details of the contents of consultations with the learning advisor and student tutor in 2016

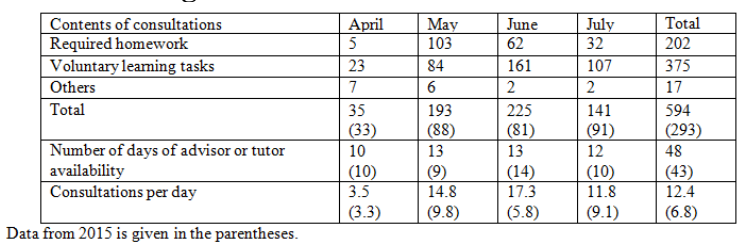

Table 2. Comparing the number of consultations with the learning advisor and the student tutor

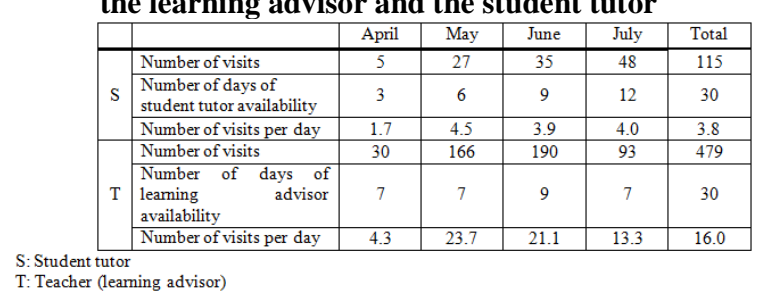

Table 2 shows a comparison of the number of students' visits to the student tutor and to the learning advisor. Both met students for consultations 30 times in 2016. However, the learning advisor had

4.2 times more consultations than the student tutor did. There was no bias of resident day and time such that the students could more easily visit the learning advisor than the student tutor. It is likely that the students must want to consult the learning advisor rather than the student tutor.

3.1.2. Submission rate for the voluntary learning tasks. Table 3 provides the frequency distribution for the students in 2015 and 2016 who received additional points by submitting the voluntary learning tasks. The overall tendency was similar in the two years. More than half of the students earned only 1 or 2 points, and only $6 \%$ of them earned the maximum of 10 points.

Table 4 shows how many students submitted two kinds of voluntary learning tasks; character input task and drill for practice.

The number of students who submitted the two tasks increased 1.9 times in 2016, and the number of submissions for voluntary learning tasks increased 3.1 times. The submission situation was different for the two tasks.

For the simple task on character input, both the number of students who submitted the tasks and the number of files on the tasks that were submitted increased 6.1 times and 5.5 times respectively, in 2016.
Table 3. Distribution frequency of each point given for the submission of voluntary learning tasks

\begin{tabular}{|c|c|c|}
\hline \multirow{2}{*}{ Additional points } & \multicolumn{2}{|c|}{ Number of students } \\
\cline { 2 - 3 } & 2015 & 2016 \\
\hline 10 & 4 & 8 \\
\hline 9 & 1 & 0 \\
\hline 8 & 1 & 0 \\
\hline 7 & 2 & 5 \\
\hline 6 & 2 & 2 \\
\hline 5 & 6 & 3 \\
\hline 4 & 6 & 11 \\
\hline 3 & 5 & 18 \\
\hline 2 & 14 & 26 \\
\hline 1 & 19 & 44 \\
\hline $\begin{array}{c}\text { Total number of } \\
\text { students }\end{array}$ & 60 & 117 \\
\hline
\end{tabular}

Conversely, for a slightly difficult task on a practice drill, both the number of students who submitted the tasks and the number of files that were submitted decreased 0.4 times and 0.7 times respectively, in 2016. The result shows that in 2016, several students wanted to repeat the simple task, but only a few attempted the difficult task and aimed for a higher standard. The submission rate was higher for an intermediate class in 2015, but was higher for a basic class in 2016. More students with a basic level of computer literacy worked on the basic voluntary learning tasks in 2016, than in 2015.

\subsection{Improvement of learning outcomes through voluntary learning tasks}

3.2.1. Comparison of learning outcomes between submission and non-submission groups. We need to verify the effect of submission of voluntary learning tasks on learning outcomes. For this, we compare the difference in learning outcomes between the group that submitted the tasks and the group that did not. Table 5 shows a comparison of the six indicators of learning outcomes for the two groups. The difference in the scores between the two groups is clear in all six indicators; the submission group had higher average scores compared to the non-submission group. This result is the same as what was found in 2015, as reported in [5].

\subsubsection{Comparison of learning outcomes from} 2014 to 2016. Table 6 shows the change in learning outcomes, such as a test for Excel, the result of the final-semester test, and an assessment result using Rasti. Rasti is vastly recognized in Japan as an assessment of information literacy, and its scores help in assessing the capability for effective use of information technology. The results clarify that the Microsoft Office test, the semester test, and the Rasti scores are declining gradually year by year, though the number of consultations has increased since 
2014. We will discuss a factor and solution for the gradual decline in students' computer literacy.

\section{Discussion}

\subsection{Effect of the voluntary learning tasks and consultations on learning behavior}

Among the 15 lessons in the first half of 2016, students had to complete and submit homework ten times. Six of those contained the tasks in the textbook and four, the tasks on the e-learning platform, NESS. The submission rate for the required homework was relatively high at $96.1 \%$. It indicates good learning behavior to submit homework. The learning advisor and student tutor have the responsibility to support students who do not fully understand the class and cannot work on the homework by themselves. As shown in Table 1, the number of visits for consultation on the homework is very large, 202 cases in 2016. Students who cannot fully understand a lesson would require support outside the class.

Table 4. Number of submission group students and submitted files.

\begin{tabular}{|c|c|c|c|c|c|}
\hline \multicolumn{2}{|c|}{ Number of submission group students } & \multicolumn{3}{c|}{ Number of submitted files } \\
\hline $\begin{array}{c}\text { Character } \\
\text { input tasks }\end{array}$ & $\begin{array}{c}\text { Drill for } \\
\text { practice }\end{array}$ & Total & $\begin{array}{c}\text { Character input } \\
\text { tasks }\end{array}$ & Drill for practice & \\
\hline 115 & 23 & 117 & 876 & 107 \\
$(19)$ & $(52)$ & $(61)$ & $(158)$ & $(163)$ & \\
\hline
\end{tabular}

As shown in Table 4, the overall number of submissions of the voluntary learning tasks increased in 2016, but the submission rate for the practice drill that was more difficult than the character input task largely decreased. The voluntary learning tasks were recommended as challenges for students who aimed at the higher level of computer literacy. It is definitely important to tackle basic input tasks for mastering the basics of computer literacy. However, at the same time, we should guide students to challenge themselves to work on the higher-level practice drill and submit it to the learning advisor. For example, it might be important that the class instructor recommends the tasks of a related practice drill in the NESS system to the current class, while maintaining that the contents of the voluntary learning tasks can be freely chosen by students.

\subsection{Points for further learning support outside the class}

4.2.1. Location of the consultation corner. The location of the consultation corner where the learning advisor or student tutor met the students outside the class was changed in 2016. As shown in Figure 2, we initially installed a consultation corner in the lobby in 2015 so that it would stand out. The students would be aware of the presence of the learning advisor, and consequently visit her. In this case, only the students who wish to ask a question regarding class would likely visit the learning advisor. In 2016, we set up the consultation corner in the computer room. Students would probably consult the learning advisor or student tutor when they encounter tasks that they are unable to solve by themselves when working on them. In this case, the students can ask questions while working on a PC and the learning advisor or student tutor can coach them through it. We should pay more attention to how easily students take action to ask for support to the learning advisor or student tutor when we plan to build learning support environments outside the class.

4.2.2. Learning support by the student tutor. Distributing a document about the methods of learning support that a learning advisor drafted up, the teacher had already instructed the student tutors by the end of 2015. In 2016, the teacher, learning advisor, and student tutor could use the web system to share information, such as the submission of the voluntary learning tasks and the learning support outside the class. The teacher met the learning advisor and student tutor to talk about the learning support situation during a particular academic school period. According to Table 2, the learning advisor consulted students 4.2 times more than the student tutor did. The student tutors had the requisite skills and knowledge of ICT Exercise, as they had already completed the course with very high grades. However, the student tutors were not professionals in teaching the lower-grade students. In contrast, the learning advisor, who must have a higher level of skills and knowledge on ICT than the student tutors, could easily support the students more suitably outside the class. This was based the fact that the learning advisor understood the progress of the class by attending the lectures as a sub-lecturer or by sharing information during meetings. It is important to build an environment where a student tutor can support students at the level of the learning advisor in cooperation with the teacher and the learning advisor.

4.2.3. Clear image of students needing consultation. It is important that students who cannot tackle homework by themselves recognize a method to solve it through learning support outside the class. Many students can solve the homework by themselves, or by helping each other without using the consultation corner. The number of students who work on homework by themselves or solve it to reach a higher level could be more in 2015 than in 2016. These students probably work well by listening to instructor's explanation in their class. Hence, they do not need to visit the consultation corner for understanding the content. We should pay attention to what support the students ask of the learning advisor. 


\subsection{Effect of the voluntary learning tasks on learning outcomes}

Table 5. Comparison of the learning outcomes (average scores) of the voluntary learning task submission and non-submission groups both in 2015 and 2016

\begin{tabular}{|l|l|l|c|c|}
\hline & \multicolumn{2}{|c|}{2015} & \multicolumn{2}{c|}{016} \\
\hline & Submission group & Non-submission group & $\begin{array}{l}\text { Submission } \\
\text { group }\end{array}$ & $\begin{array}{l}\text { Non-submission } \\
\text { group }\end{array}$ \\
\hline Total semester & 88.3 & 79.3 & 90.4 & 80.8 \\
\hline Homework & 22.0 & 20.0 & 21.4 & 19.8 \\
\hline $\begin{array}{l}\text { E-leaming for } \\
\text { WordExcel }\end{array}$ & 14.4 & 13.2 & 15.0 & 14.0 \\
\hline Test for Word & 8.3 & 8.1 & 7.5 & 7.1 \\
\hline Test for Excel & 8.5 & 7.9 & 7.9 & 6.9 \\
\hline Final-semester test & 12.3 & 11.6 & 7.9 & 7.0 \\
\hline
\end{tabular}

Table 5 and [5] show that in 2015 and 2016, the student group that submitted the voluntary learning tasks had a higher average point of learning outcomes. The reasons as to why the students submitted the voluntary learning tasks could vary. For instance, they might be interested in ICT and so tackle the tasks eagerly, or they are not good at ICT and so want to catch up to the class, or they are not interested in ICT but wish to get additional points. As shown in Table 3, in 2015 and 2016, more than $70 \%$ of the students achieved less than four additional points. Hence, most of students seem to submit the tasks only a few times. On the other hand, the number of students who achieved full additional points increased in 2016; twice as much as in 2015.

While keeping in mind the various reasons for the students' commitment to the voluntary learning tasks, we should investigate how to enhance learning outcomes through working only on the required homework, and how to improve the learning outcomes further through actively working on the voluntary learning tasks.

\subsection{Comparison of learning outcomes over three years}

Table 1 and [5] have demonstrated that assigning voluntary learning tasks stimulates students to consult the learning advisor and the student tutor, for completing them outside the class. The submission group shows higher learning outcomes than the nonsubmission group. Thus, in view of the learning outcomes in the same year, it becomes clear that the assignment of the tasks affects active learning behavior and elevates the learning outcomes of the submission group. Two questions emerge here. How has the overall learning outcome changed after assignment of the voluntary learning tasks in 2015 ? Table 6 also shows that the learning outcome scores decline every year from 2014 to 2016 . Why does this tendency occur?
Table 6. Comparison of learning outcomes over three years

\begin{tabular}{|l|c|c|c|}
\hline & 2014 & 2015 & 2016 \\
\hline Test for Word & 8.5 & 8.0 & 7.2 \\
\hline Test for Excel & 8.7 & 7.9 & 7.2 \\
\hline Final-semester test & 8.4 & 7.7 & 7.7 \\
\hline Rasti test & 471.5 & 448.9 & $*$ \\
\hline $\begin{array}{l}\text { Assignment of voluntary } \\
\text { leaming tasks }\end{array}$ & No assignment & Assignment & Assignment \\
\hline $\begin{array}{l}\text { Number of consultations } \\
\text { outside the class }\end{array}$ & 142 & 293 & 594 \\
* Rasti test was not conducted in 2016 &
\end{tabular}

Sagisaka and Chiba [2] investigated the decline in computer literacy among university students because of the daily use of smartphones in Japan, and so staying away from PCs. An annual comparison in computer literacy of the first-year students at their university was performed from 2012 to 2015. The results show that the frequency of use of the PC at the entrance to the university is gradually declining every year. Inversely, smartphone possession rate is gradually increasing every year. The scores on the keyboard input tasks significantly decreased every year $(8.19,7.81,7.87$, 7.85 points). The scores on the function calculation and graph making tasks in Excelalso significantly decreased every year (5.5, 4.38, 4.3,4.22 points).

Additionally, for the question "Which do you feel is easier for inputting a character: smartphone or PC?," $73 \%$ of the students answered smartphone while only $10 \%$ answered PC. Sagisaka and Chiba [2] discuss that it is important that teachers make students realize the significance of computer literacy when they assign the tasks. Similarly, at our university, the increase in smartphone use would cause lesser use of PCs. It is necessary to examine the amount and degree of difficulty of the required homework in 2017. Additionally, we should support students in making a habit of using PCs at any time when tackling homework and voluntary learning tasks.

\subsection{Elevating the levels as an active learner}

Sakai et al. [4] proposed a method for assessing active learners (AL) to implement a learning environment to train active learners stepwise. Sakai et al. [6] created a questionnaire survey on students' learning attitudes and behaviors, and presented the data analysis measuring AL level of each student. Based on this, we establish the following four AL levels as attitudes of proactive learning.

1. At AL level 0: Students do not complete homework at all.

2. At AL level 1: Students are not eager to tackle homework and have a low submission rate.

3. At AL level 2: Students tackle homework with higher enthusiasm and with the cooperation of others, such as the learning advisor.

4. At AL level 3: Students can tackle homework alone proactively. 
5. At AL level 4: Students can support other students in their homework.

In the future, we should lead students who do not work on their homework every time to develop a habit of tackling it eagerly, aiming toward a transformation from AL level 0 to 1. Additionally, we should lead students who cannot solve homework or higher-level tasks to complete it with the support of a learning advisor, aiming toward a transformation from AL level 1 to 2 . Furthermore, we should lead students who complete homework with the help of a learning advisor to do it by themselves, aiming toward a transformation from AL level 2 to 3.

The student tutor should support students, which is equivalent to an action at AL level 4. In the Learning Station at our university, similar to the student tutor for ICT Exercise, the uppergrade student tutor stayed on specific days and times to support the lower-grade students who need consultations for making reports or for getting a certificate qualification. Furthermore, students in every department spontaneously formed learning groups by themselves, and taught each other. We should lead students to support their friends who can tackle homework with them, aiming toward a transformation from AL level 3 to 4. Our faculty members need to report and share good practices with one another so that the students can support each other's learning.

\section{Acknowledgements}

We appreciate the contribution of Work Academy Co., Ltd. They provided information on lesson management, learning behavior, and other detailed information and data on the learning outcomes of students. We would like to thank Editage (www.editage.jp) for English language editing.

\section{References}

[1] I. Abe and K. Sakai, "Issues and improvement of common information literacy education," Japan Society for Information and Systems in Education Research Report, 29(5), 2015, pp. 123-126. (in Japanese)

[2] T. Sagisaka and S. Chiba, "Freshmen students' information literacy and IT skills in the Faculty of Foreign Studies: 4 years' results of the ICT skills assessment tests and computer use questionnaires for first-year undergraduate students," Reitaku University Journal, 99, 2016, pp. 35-49. (in Japanese)

[3] K. Sakai and I. Abe, "A method for mastering the use of information application and information literacy," Japan Society for Information and Systems in Education Research Report, 26(6), 2012, pp. 61-68. (in Japanese)
[4] K. Sakai, I. Abe, and A. Inui, "Creating organized support systems for improving students' learning and performance," Research Report of Japan Society for Educational Technology, 14(5), 2014, pp. 275-282. (in Japanese)

[5] K. Sakai, I. Abe, D. Fujita, and K. Naka, "Increasing the efforts made for voluntary learning tasks in information literacy classes as the outcome of deploying learning support," Japan Society for Information and Systems in Education Research Report, 30(5), 2016, pp. 51-58. (in Japanese)

[6] K. Sakai, D. Fujita, C. Ozawa, A. Inui, I. Abe, and H. Yamashita, "Analysis of a questionnaire survey aimed at the development of an active learners level assessment," Research Report of Japan Society for Educational Technology, 16(1), 2016, pp. 5-12. (in Japanese) 